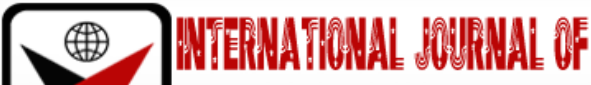

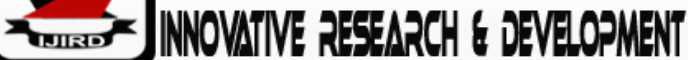

ISSN 2278-0211 (Online)

\section{Psychosocial Support for Newly Recruited Teachers of English Language in Kenya}

\author{
Sophia Atieno Oriwo \\ Ph.D. Researcher, Department of Curriculum Instruction and Educational Media, \\ School of Education, Moi University, Kenya \\ Peter L. Barasa \\ Deputy Principal, Academic and Research, Alupe University College, Kenya
}

\begin{abstract}
:
Various forms of support frommore experienced teachers help Newly Recruited Teachers (NRTs) to quickly adjust to the expectations of the new job as well as the respective place of work.Today, support of NRTs is even more crucial considering that since 1998, the Teachers Service Commission (TSC)currently established under Article 273 (1) of the Constitution of Kenya (2012); the sole employer of teachers in Kenyaapplies a demand-driven-teacher recruitment formula. Teachers are recruited and posted subject to availability of vacancies in any part of the republic of Kenya. The posts are advertised and recruitment follows successful interview conducted in the schools with vacancies or of late in certain central venues that cater for particular sub counties.TheNRTs face a myriad of challenges given that many of them get employed in environments they are not familiar with and sometimes in counties that are far away from their counties of origin. Unfamiliar environments are bound to create heightened feelings in an individual. The NRTs are not an exemption to this. They obviously needpsychosocial support:-opportunity to have someone to talk to and need to feel comfortable in asking for advice and assistancesuch as helping them feel at ease, attention for stressrelief, and stimulating self-confidence.This paper seeks to report the findings of a study with regard to such support strategies that various school managements use to get the NRTs acclimatize to their new schools in particular and the teaching profession in general. It also makes recommendations for improvement of such support in pursuit of better teaching environments for quality education in Kenya.
\end{abstract}

Keywords:Newly recruited teachers, psychosocial support, wellbeing, personal welfare

\section{Introduction}

Unlike people in most other professions, teachers hardly get the opportunity to grow into the profession gradually. Beginning teachers usually have the same responsibilities and duties as senior teachers. They get a full schedule of teaching hours, the sole responsibility for teaching their lessons and other responsibilities as deemed necessary by the school principal. Unlike senior teachers, however, the novice teachers lack the routine that comes with experience. Many of them struggle with teaching issues, such as classroom management, student assessment, as well as students' personal problems. Apart from these teaching issues, beginning teachers also have to socialize within the school. They have to become members of an organization, find their own place in the school, and gain the appreciation of their new colleagues. This is not always an easy process as beginning teachers often face resistance and sometimes skepticism from their senior colleagues (Kelchtermans\& Ballet, 2002).

The first years of teaching have a tremendous impact on the beginning teacher and often lead to feelings of low self-esteem, stress, and sometimes even burnout, with attritionas a possible consequence. The NRTs have to embark on a socialization process in the school.They have to adjust to the procedures and culture of a school. Ultimately, they have to earn the appreciation of their new colleagues (Kelchtermans\& Ballet, 2002). For many teachers, the induction period is an intense phase in which the learning curve is steep and emotions run high. To meet the psychological needs of beginning teachers, many mentoring researchers stress the importance of supporting them with an induction programme that includes the necessary personal and emotional support for their wellbeing.

Well-being refers to 'general healthy and happiness' (The New Oxford Learners Dictionary of Current English). In research, well-being has been construed as a multi-dimensional concept including affective, cognitive, behavioural, psychosomatic, and professional dimensions (Van Horn, Taris, Schaufeli, \&Schreurs, 2004). Usually, well-being is interpreted as a primarily affective state. Engels, Aelterman, Van Petegem, and Schepens (2004) defined well-being as ' $a$ positive emotionalstate that is the result of a harmony between the sum of specific context factors on the one handand the personal needs and expectations towards the school on the other hand.' This is echoed by VanPetegem, Creemers, Rosseel, \&Aelterman (2006). More important for thewell-being of beginning teachers than any characteristic of the formal inductionprogramme is the school culture: the collegiality and informal support experienced bybeginning teachers. 
Schools attempt to increase the well-being of beginning teachers, and thereby prevent attrition, mainlyby focusing their induction programmes on the emotional support and socialization process within the school (Wang \& Odell, 2002).

Three important aspects of beginning teachers' well-being on which an induction program might have a significant influence have been distinguished. These aspects are: the beginning teachers' feelingsof isolation, the beginning teachers' feelings of appreciation by colleagues, and thebeginning teachers' feelings of self-confidence.Helsel, DeWert, Babinski, and Jones (2003) showed that an online support community can alsocontribute to the well-being of beginning teachers during their induction period. They reported on a positive effect on a number of variables related to well-being, such as confidence inteaching, reduced feelings of isolation, and enthusiasm for work.It has thus been shown that induction programs are, generally speaking, relevant for beginningteachers' well-being. In addition, a number of studies have also shown positive effects of induction programs on theretention rate amongst beginning teachers (Smith \& Ingersoll, 2004), which is often the main reason for schools to want to contribute tothe well-being of beginning teachers.

\section{Methodology}

The approach used in the study was solely qualitative and adhered to the tenets of qualitative research as proposed by researchers (e.g. Mason2002,Lichtman 2006,Gerring 2007),Dornyei 2007),Creswell2009).Data were generated through semi-structured interviews, focused group discussions and document analysis.The target population comprised newly recruited secondary school teachers of English, practicing teachers of English who had taught for 5 years and above, heads of subject or heads of department all of whom were teachers of English and school deputy principals/principals in secondary schools in UasinGishu County. These were from 47 secondary schools which had recruited English language teachers in the years 2015- 2017. Purposive, Stratified and Simple Random sampling techniques were used to identify a total of 54 participants for the study distributed as follows- 18 newly recruited teachers (mentees) ,18 heads of department- languages/ heads of subject-English and 18 deputy principals/ principals, (mentors) drawn from all the categories of schools, that is, national, extra county, county, sub county and private.

The interviews were audio-recorded then transcribed. 'Member checks', or the participant's reading of the data for comments and interpretations, crucial for establishing credibility in a qualitative study was undertaken. The mentors and mentees read, suggested some amendments, and then authenticated the final draft of the transcriptions. Consequently, their clarifications helped shape the final written product. The data were coded into thematic categories and important quotations identified and used to illustrate the themes. This allowed the reader to have the respondents' voices verbatim.

\section{Data Analysis}

The findings of the study suggested that in fairly limited cases, beginning teachers were supported by people (mentors and others) who were 'there for them' - accessible, willing and able to listen, and act as a sounding board. These were colleagues who treated them as a 'whole person' and had regard for their practical, emotional, as well as professional needs, for example by providing encouragement, reassurance and 'positive strokes' making them feel welcome and 'safe' within their schools, and providing them with additional or detailed information about what they needed to make themselves comfortable.

However, in some of the cases, the new teachers themselves sought help from more experienced teachers who were caring, friendly, and not overly critical. It is in very few cases that the schools purposed to undertake the activity as a school policy. The following key points were distinguished:

\subsection{Nature of Support}

The support provided was in two main forms:personal welfare matters and financial wellbeing.

\subsubsection{Personal Welfare Matters}

Psychosocial support mainly entailed personal welfare matters.The NRTs reported personal support received and mentors on the other hand the support they gave. It addressed the human factor with regard to beginning teachers' need to feel accepted and supported at a personal level. One mentor quipped that the teachers of English are warm and welcoming people in contrast to those of humanities and the sciences. It was therefore not uncommon to get information about a social tradition on the first meeting in which the mentor and mentee set to establish connections, tracing shared links such as the universities the NRT attended, which part of the country they come from and so on. Some of the mentors and the HODs took this further - exploring mutual interest, likes and dislikes and even life stories. Others were more reticent, preferring to focus on the informational and professional aspects of the relationship with their beginning teacher and keeping off personal life private.

Most of the beginning teachers said that they received moral support. A number of mentors also reported that this was the activity they performed the most. Personal support by the mentor attempted to: provide assistance to the mentee on a continuing basis, making them aware of and responsive to problems known to be common to beginning teachers, assisted them build personal and professional self-esteem and helped them balance the many demands placed on them by the job. A few specific activities that were reported to have been used by mentors or the willing older teachers who were keen on emotional support to ease the tension included: take a coffee break or lunch together, share a walk to the bus stage or locality, give suggestions for acquiring scarce resources, offer an invitation to a small get-together with other colleagues and direct them to the guidance and counselling personnel within the school. These are a few among many other strategies used. These were the various ways of making the NRT comfortable as provided for in the quote below by a mentor: 
That one for sure, we do it quite a great deal, as an individual I even take them out for a cup of tea and then share with them my experience. They open up, they also share what they are going through, so in the process you tell them how to go about the various situations. So as individual teachers we also learnt how to identify those who appear frustrated. We have like two now who are very frustrated and very worried because they feel like the life in this institution is too much for them and they would opt to go for transfer because of that. But we keep on encouraging them, giving them materials for teaching, teaching materials which we may have at a personal level, advising them on how the approach of teaching and with our experience we can make them cope with this stressful working environment.

\subsubsection{Financial Wellbeing}

There is also concern for financial wellbeing just as much as career or professional advancement. An NRT intimated that she was even informed on how she would improve herself financially. This was to be by joining the teachers Sacco as soon as she got her salary flowing. She was also directed on professional or career matters for the future when she would mature for promotions. There is also a mentor who hinted on the same. These two quotes capture their remarks:

Teachers who are particularly in the Sacco are the ones who gave a lot of orientation on benefits of being in a Sacco.

...as a mentor we also teach them financial management, on how they should save, opening an account with Mwalimu Cooperative, those are very important things.

\subsection{The Support Providers}

The HODs are the people in the institutions who relate a lot with the NRTs. They are the second group to interact with the new teachers after the principals. Getting the NRT settle could be said to rest squarely on their shoulders so they take it upon themselves to address their fears and concerns. One HOD had this to say:

It is true that a new teacher can have emotional issues ... when I encounter the teacher, as HOD, that is part of what I address one on one. I address what are their fears, like maybe the teacher fears that the community will be hostile to his way of teaching so I go out of my way to ensure no such thing exist. I go out of my way to counsel them on how to relate with other teachers. I also warn the new teachers that when meeting a new society to expect all types of people.

In some isolated cases, members of the Guidance and Counselling department in the school offered counselling services.

... in my school I also double up as a guidance and counselling chairperson, so sometimes we receive cases of teachers. The new teachers feeling strange, feeling they feel they are in a place where they don't belong. But through the guidance and counselling, we normally call these teachers aside regardless of whether they belong to our department and we try to assist them, by asking them if there are any challenges they are facing.

In yet other scenarios, the teaching staff welfare took charge. These are organizations in schools that deal with the wellbeing of teachers in individual schools. The concerns of such groups are mainly to do with social issues among the teachers including seeing to it that the staff is cohesive. Some of their activities involve organizing get together sessions like joint special meals and the like. It is therefore not surprising that in some schools they are also charged with the responsibility of looking into the basic emotional requirements of the NRT at these initial stages of their entry into the teaching career as expressed below first by a quotation from a mentor then another by a mentee.

But then through the head of department or the other teachers who teach the subject we try to accommodate them, to help them fit in but it's not that easy, there are many that stay on their own for quite some time but we encourage through the teaching staff welfare to at least befriend them and show them around so that they fit in and if any extreme cases then the teacher of guidance and counselling can be called upon to assist or if.....then the school chaplain...

First, the members of the department were very friendly. So they made life in a new school bearable. Emotional needs there is a system. There is a teacher in charge of the teaching staff welfare. It is within this docket that even the get together meetings for the staff are organized and they have quite a number like a joint lunch out for all or even at the departmental level. She is the one who assisted me emotionally by linking me with people who have the experience to sort out my needs in the various fields. These were basically the older teachers.

The experiences of mentees in the private schools were particularly different. There, the emotional needs of the beginners were better taken care of than in the public schools. In one, the principal was very friendly and concerned. The principal would invite teachers for evening meals in her house and this provided a natural atmosphere for bonding. Attendance was of course not compulsory so some teachers did not always attend. The mentee had this to say:

We would have talks that were not very serious in the house........ in the principal's house. We used to call it house number one. We would have talks in the evening when we would just talk generally.... Emotionally I was not affected. The people were quite friendly. If I had any problem that was very serious I can't say I discussed it with anyone in that school but of course I discussed it elsewhere. Yeah but it wasn't about the school at that point. Yeah.

In yet another private school, the NRT had the benefit of a very friendly mentor who would walk him around the locality, engage him in playing a game of chess and even encourage him to address the mentor using the first name to remove any traces of extreme formality that impede easy bonding. He said:

Yes. We would also take walks around the school, the villages around- orientate me to the community... he wouldn't let me call him an old man. He's called Peter. And I'm also Peter. He prefers me calling him Peter, makes 
him feel younger, that brought us a little close and my eagerness to learn, his eagerness to teach. Yea, a bond grew... then maybe playing chess. He's a good chess player. Playing chess in the staffroom would help me relax, forget a few things, make me settle down. He knew that I would replace him and he used to tell me, 'I want something better than me...I want you to be better than me.

\subsection{School Size and Gender}

Another scenario concerning emotional issues touched on school size, that is, the number of teachers and students. A mentee reported that his school was small in terms of both student and teacher population and as such bonding with one another among the teachers was easily achieved. He also brought out a dimension that touches on gender. He intimated that the men bonded more easily than the ladies. The quote below attests to this.

Mine being a small school we bonded very easily because in no time I was already familiar with all the teachers who were sitting in the staffroom. Again this was a fairly new school so other than the principal and the deputy, the rest of us did not have a very big age gap so we interacted closely because we shared a lot of interests. So, after classes it was very common to get us walk out of school together and most of the time go to socialize together. I did not feel stressed and of course unlike the ladies,we men get along with each other much faster.

However, there were contrary reports by some of the NRTs in extra county, county and sub county schools most of which have large numbers of teachers. They reported a lot of discomfort during the initial days of employment. They said that there was very little socialization if any. In fact, in one school a mentee reported that the local language was used in the staffroom and this compounded the problem of being new in an environment far away from home. A mentee who experienced this said:

I must say it was not very easy. The most frustrating was the language barrier. This was a challenge, especially for those coming from other counties who did not understand the common language of communication used in this particular school. We were very few and felt left out because we did not understand the local language used by majority of the other teachers who were natives of the county. During the breaks I would just sit and watch them talk but would not know what they were talking about and sometimes they would laugh and I would feel left out and a bit idiotic.

In many such schools, the new teachers had to device their own ways to make themselves comfortable. Some looked for colleagues who appeared welcoming and hooked up with them. These colleagues did not necessarily belong to the mentees departments. In very extreme cases the findings reveal that the NRTs were left with the only option of turning to family and friends back in their homes. They even doubted whether they had chosen the right profession. These stressing circumstances are further evidenced in the quotes below:

Yeah. The first time I felt I was uncomfortable because after I was given my lessons, there was no one to tell me what to do. I had to go to the teachers request them to tell me this class at what time where the timetable is and so forth. And then this school has a problem the TT keeps on changing. And so, you are new, you have been given a TT then after 3 days, there is a change so you feel very uncomfortable again you have to look for a teacher to ask and again you don't know who is a new teacher like you or who is the one you are supposed to ask so I was very uncomfortable... the challenges were stressing me. I was so depressed. For some time I felt like this is a wrong profession ...Yes my personal and emotional needs were catered for back at home and not in school.

I had to learn the hard way. In fact a volunteer came to my assistance. I guess he must have read form my face or so that I was stressed. I decided to be going to that teacher because I was frustrated... But again it was limited because this teacher was male and as such after official school hours it was not possible to be with him so I really felt lonely after school. In fact, I would really long for the weekends to come so that I would visit home or relatives but again this was not frequent because I had a lot of financial constraints.

This next excerpt brings out an unbelievable occurrence. It was surprising that in some schools, the older teachers who were supposed to assist the new teachers settle complained that the new teachers had been given responsibility. This most obviously would have been frustrating to the novice and even heighten her emotional stress but surprisingly she remained calm. This reaction to the situation has brought in the personality dimension in the findings. It comes out clearly that as to whether the novice would be stressed or not depended to some extent on their personality traits as expressed by this mentee.

Emotionally I can say I was a little bit stressed because you could overhear others saying this one just came in the other day and she is given responsibility and she does not have such experience, once in a while you could find people badmouthing but I think the administration came in strongly and supported me.I refused to be isolated. I think I will attribute that to my outgoing nature

The key issues raised are summarized in Table1.

- Key actors were HODs, Members of Guidance and Counselling Department, Staff Welfare Officials

- Generally, concern was for the emotional and social wellbeing of the new teacher.

- In some cases, there were concerns on financial matters pertaining to savings.

- More ready bonding and socialization in the public schools with lower teacher population

- Socialization in private schools was better than that in public schools

- Where the NRTs failed to get warmth in the schools, they sought refuge from relatives back in their homes.

Table 1: Summary of Key Issues on Psychosocial Support 


\section{Discussion}

Research literature dwells a great deal on this type of support. Even though at the core of support for NRTs should first and foremost be a professional one, some degree of personal connection can help overcome tensions and promote trust. The extent to which the relationship will become personal will likely depend on the beginning teachers' need for support at that level, and their comfort zones for disclosure and openness. Some beginning teachers will be away from home for the first time, and if their first jobs are in communities very different from those they are used to, they are bound to need social support. In this study, it was reported that most of the teachers of English are generally welcoming by nature as such, the mentors did not have to take on the full responsibility of ensuring this occurs.

Strategies directed towards emotional needs of the NRT arepsychosocial and involve role modelling, confirmation, counselling and providing emotional support. The psychosocial mentor role is to change the social circumstances of the protégé, to impact the protégé personally and to serve as a role model to encourage, counsel and support the protégé. The mentoring relationship is based on the formation of trust and emotional attachment. The goal is for the protégé to identify with and imitate the mentor, receive reinforcement for positive behaviours and attitudes, learn how negative and inappropriate behaviours may interfere with emotional growth, and develop educational and work goals.

Emotional support is a key element in the whole process of mentoring. The first year of teaching can be somewhat chaotic, emotionally draining and physically exhausting. Beginning teachers are confronted with the real world of the classroom and respond emotionally to the challenges they face. The first year is seldom exactly what they thought it would be. When mentoring first-year teachers, it is important to keep in mind their emotional state as they move through these various stages. One of the greatest needs of first-year teachers is emotional support in personal and professional matters. Mentors, however, are not the only ones supporting beginning teachers. It could be that the emotional support could best be provided by other teachers on the staff, or by one particular experienced teacher the beginning teacher has befriended. Mentoring apparently is a shared task; the mentor has volunteered to take on the bulk of the responsibility but can be helped by other willing volunteers who have the best interest of the beginning teacher at heart.

An article-Mentoring Beginning Teachers: Lessons from the Experience in Texas Policy Research Report (2000) emphasizes this support in this development stage considered necessary by researchers and practitioners. The report cites Feiman-Nemser (2003).This support has been found critical for new teachers who come to an array of new responsibilities with little time and few resources to direct toward transitioning into those responsibilities.

Psychological support addresses the most immediate personal and emotional needs of teachers new to the classroom. This kind of support centres on protecting the new teacher from isolation by providing him or her with moral support and suggesting ways in which to balance the unfamiliar demands and expectations of students, parents, and the school at large. Here, veteran teachers create an emotional safety net by: serving as a sounding board and assuring beginners that their experience is normal, offering sympathy and perspective, and providing advice to help reduce the inevitable stress. Alberta Teachers' Association (ATA), Beginning Teachers' Handbook (2003). Program Handbook: Mentoring Beginning Teachers summarizes this as support provision in which the mentor is a confidant, advisor and friend.

Befriendingfunction of mentoring provides protégés with someone to whom they can speak freely.

With regard to emotional support, the study revealed that to a large extent, it was the one strategy that was used widely in majority of the schools regardless of the category. In as much as the details of attempt at providing a 'soft landing' for the NRTs was not necessarily uniform, each attempt had the comfort of the novice as the nucleus of the activity. There were just a few isolated cases that reported the contrary.

\section{Conclusion and Recommendations}

Kenya, like most developing nations, has yet to establish a formal teacher educational policy on all forms of support for beginning teachers. At the secondary school level in which the study was based, schools, sub counties, counties, regions and even the nation hardly offer any organized support of whichever manner for the beginning teachers. Additionally, if there are any, there are not formal and thus do not meet the threshold expected. Attempts by individual schools at some form of emotional support as exhibited by the findings of the current study revealed that from one school to another , much variance existed mainly with regard to duration, structure, and intensity as confirmed by mentoring scholars and researchers such as (Wynn et al., 2007; Ingersoll \& Smith, 2004).

In order to effectively serve beginning teachers, NRT support activities must possess certain attributes that are aligned with a national vision for teacher support and preparation which currently is non- existent. Such essential attributes include providing support in a bundled format (Wynn et al., 2007; Ingersoll \& Smith, 2004), offering beginning teachers available and reliable mentors from the same field (Ingersoll \& Smith, 2004;), affording opportunities for professional collaboration), affording opportunities for lesson observations and supporting psychological, instructionrelated, and development needs (Wynn et al., 2007). Additionally, all of this support should be offered in a format that works to alleviate additional stress for beginning teachers.

Recommendations for emotional support strategies mainly targets school principals. These are the agent of the teachers' employer TSC. They work very closely with the NRTs and it is their word that the commission relies on for confirmation of NRTs employment to permanent and pensionable status. Proper management practices by them lead to discipline and excellent performance in a number of areas which come in handy in the professional development and wellbeing of the NRT. The principal is charged with the responsibility of planning, budgeting and ensuring appropriate use of all teaching and learning resources. They also manage staff to sustain high morale, motivation, high integrity and appropriate work ethics and ensure school/community relations, health, security and welfare for harmonious and peaceful co-existence based on acceptable conduct and behaviour of all in the school community. Therefore, they should: 
- Set up school structures and release time that enable mentors, and experienced teachers to work together with new teachers.

- Create regular opportunities for interaction between new and experienced teachers. This kind of interaction, which includes both formal and informal exchanges, is characterized by classroom observations currently provided for by Teacher Performance Appraisal and Development (TPAD) initiative, spontaneous advice, and group meetings. NRTs value and benefit from group conversations with colleagues, which are facilitated if veterans and novices are placed in close proximity. This calls for improved infrastructure in terms of subject offices which enable members to sit together thereby facilitating socialization.

- Pair new teachers (one-to-one) with experienced teachers who have the relevant skills, content knowledge, expertise and willingness to serve as coaches or mentors.

- Cultivate a professional culture that recognizes the needs and skills of new teachers and promotes ongoing interactions of teachers across experience levels.

- Minimize non-teaching responsibilities for novice teachers so that they have time for a full range of induction activities, more importantly mentoring.

- Recognize the difference in skill levels between novice and veteran teachers and adjust responsibilities accordingly so that new teachers are not given the most difficult teaching assignments.

\section{References}

i. Bullough, R.V. Jr. \& Draper, R. J. (2004). 'Mentoring and the emotions.'Journal of Education for Teaching, 30(3), 271-288

ii. Creswell, J. W. (2009). ResearchDesign; Qualitative, Quantitative and Mixed Method ((3 ${ }^{\text {rd }}$ ed). London: Sage Publications Limited.

iii. Dawo, I.J. (2011). Key to Quality Teaching in Kenyan Schools. European Journal of Educational Study Selected for U.S.National Study [press release]. Princeton, NJ: author. Retrieved from http://www.ets.org/news/05032101.htmlies 3(3), 513

iv. Dornyei, Z. (2007). Research Methods in Applied Linguistics: Quantitative, Qualitative and Mixed Methodologies. Oxford; University Press

v. Engels, N., Aelterman, A., Van Petegem, K., \&Schepens, A. (2004). Factors which influence the well-being of pupils inFlemish secondary schools. Educational Studies, 30(2), 127-143.

vi. Feiman-Nemser, S. (2003). What new teachers need to learn. Educational Leadership, 60(8), 25-29.

vii. Gerring, J. (2007). Case study research: principles and practices. New York: Cambridge

viii. University Press.

ix. Ingersoll, R. \& Smith, T. (2004). Do Teacher Induction and Mentoring Matter? NAASP Bulletin, 88(638), 28-40. available at www.gse.upenn.edu/pdf/rmi/doteacher-inductionandmentoringmatter-2004.pdf

X. Kelchtermans, G., \& Ballet, K. (2002). The micropolitics of teacher induction. A narrative-

xi. Biographical study onteacher socialization. Teaching and Teacher Education, 18, 105-120

xii. Kessels, C. (2010). The Influence of Induction Programs on Beginning Teachers' Well-being and Professional Development. Netherlands Organization for Scientific Research (nwo).Project no. 411-02-203

xiii. Lichtman, M. (2006). Qualitative Research in Education: A user's guide. London: Sage

xiv. Publications

xv. Mason, J. (2002). Qualitative researching (2nd ed.). London: Sage Publications.

xvi. Republic of Kenya (2010). The Constitution of Kenya. Nairobi: Government Printers.

xvii. Simatwa, E.M.W. (2010). Induction Needs of Beginning Teachers in Public Primary Schools:

xviii. A Case Study of Bungoma East and North Districts. Educational Research Journal. Vol. 1(10) pg 481-491 ISSN:2141-5161 http://www.interesjournals.org

xix. Stuart, L. (2002). What New Teachers Need: A Principal's Perspective. Principal Vol 81(4) pg 18-21.

xx. Van Petegem, K., Creemers, B. P. M., Rosseel, Y., \&Aelterman, A. (2006). Relationships

xxi. Betweenteacher characteristics, interpersonal teacher behaviour and teacher wellbeing. Journal of Classroom Interaction, 40(2),34-43.

xxii. Van Horn, J. E., Taris, T. W., Schaufeli, W. B., \&Schreurs, P. J. G. (2004). The structure of Occupational well-being: A study among Dutch teachers. Journal of Occupational Psychology, 77, 365-375.

xxiii. Wynn, S., Carboni, L., \&Patall, E. (2007). Beginning teachers' perceptions of mentoring, climate, and leadership: Promoting retention through a learning 